\title{
Heat stress pretreatment decreases lipopolysaccharide-induced apoptosis via the p38 signaling pathway in human umbilical vein endothelial cells
}

\author{
ZHIFENG LIU ${ }^{1-3^{*}}$, TIANYU ZHONG ${ }^{1,4 *}$, DONG ZHENG ${ }^{2}$, \\ INGA CEPINSKAS ${ }^{2}$, TIANQING PENG ${ }^{2}$ and LEI SU ${ }^{1,3}$
}

\author{
${ }^{1}$ Department of Intensive Care Unit, General Hospital of Guangzhou Military Command, Guangzhou, Guangdong 510010, \\ P.R. China; ${ }^{2}$ Critical Illness Research Centre, Lawson Health Research Institute, University of Western Ontario, \\ London, ON N6A 4G5, Canada; ${ }^{3}$ Key Laboratory of Hot Zone Trauma Care and Tissue Repair of PLA, \\ General Hospital of Guangzhou Military Command, Guangzhou, Guangdong 510010; ${ }^{4}$ Medical Laboratory, \\ First Affiliated Hospital of Gannan Medical University, Ganzhou, Jiangxi 341000, P.R. China
}

Received April 21, 2015; Accepted March 7, 2016

DOI: $10.3892 / \mathrm{mmr} .2016 .5303$

\begin{abstract}
The present study aimed to investigate vascular endothelial apoptosis, and the regulatory molecules involved in the condition of heatstroke caused by direct hyperthermia due to high core temperature and gut-derived endotoxemia. Human umbilical vascular endothelial cells (HUVECs) were isolated and treated with heat stress $\left(43^{\circ} \mathrm{C}\right.$ for $\left.1 \mathrm{~h}\right)$, lipopolysaccharide (LPS; $1 \mu \mathrm{g} / \mathrm{ml}$ ), or a combination of heat stress pretreatment followed by LPS. Caspase-3 activity, DNA fragmentation, and cell viability, determined using a 3-(4, 5-dimethyl thiazol-2-yl)-2,5-diphenyl tetrazolium bromide assay, were measured to examine cellular apoptosis. Changes in the expression levels of heat shock protein (HSP) 27, HSP90 and B-cell lymphoma 2 (Bcl-2), and the phosphorylation of p38 were detected using Western blot assays. The specific inhibitor
\end{abstract}

Correspondence to: Professor Tianqing Peng, Critical Illness Research Centre, Lawson Health Research Institute, University of Western Ontario, 800 Commissioners Road East, London, ON N6A 4G5, Canada

E-mail: tpeng2@uwo.ca

Professor Lei Su, Department of Intensive Care Unit, General Hospital of Guangzhou Military Command, 111 Liuhua Road, Guangzhou, Guangdong 510010, P.R. China

E-mail: slei_icu@163.com

*Contributed equally

Abbreviations: LPS, lipopolysaccharides; HS, heat stress; HUVECs, human umbilical vascular endothelial cells; SIRS, systemic inflammatory response syndrome; MAPK, mitogen-activated protein kinase; HSP, heat shock protein; Bcl-2, B-cell lymphoma 2

Key words: heatstroke, endotoxin, injury, mitogen-activated protein kinase, endothelium of p38, SB203580, was also used. LPS induced endothelial apoptosis, as indicated by increased caspase- 3 activity, a high level of DNA fragmentation and low cell viability. LPS also increased p38 phosphorylation and decreased the expression levels of HSP27, HSP90 and Bcl-2. Heat stress pretreatment inhibited LPS-induced cellular apoptosis, increased the phosphorylation of $\mathrm{p} 38$, and increased the expression levels of HSP27, HSP90 and Bcl-2. Pretreatment with SB203580 had effects similar to those of heat stress in the amelioration of LPS-induced effects. These findings demonstrated that heat stress pretreatment decreased LPS-induced Bcl-2-associated apoptosis in HUVECs by attenuating p38 activation, thereby increasing the expression levels of HSP27 and HSP90.

\section{Introduction}

Heatstroke is an illness, which frequently occurs during the summer. Although substantial progress has been made in the prevention and treatment of heatstroke, its mortality rate remains between 20 and $70 \%$. The possible reason for the high mortality rate of heatstroke is the poor understanding of the underlying molecular mechanisms, which has resulted in a lack of targeted and effective treatments (1). Studies have suggested that heatstroke and its progression to multiple organ dysfunction syndromes are due to a complex interplay between the acute physiological alterations associated with direct heat injuries, the inflammatory and coagulative responses of the host, and systemic inflammatory response syndrome (SIRS) secondary to immediate heat injury as the leading cause (2-5). It is currently hypothesized that intestinal dysfunction is the initiating and stimulating factor leading to SIRS, and infections caused by intestinal bacteria and endotoxin translocation have been clinically implicated (2). Studies investigating heatstroke have also revealed that intestinal lesions are common, and intestinal-derived endotoxemia has been observed in cases of heatstroke $(6,7)$. Thus, during heatstroke, tissues and cells are stimulated by direct heat and subsequent gut-derived endotoxemia. 
Vascular endothelial cells line the entire circulatory system from the heart to the smallest capillaries. These cells have distinct and unique functions, and are also considered to be involved in SIRS $(8,9)$. Typically, the heat involved in heatstroke is considered to be directly cytotoxic, and endothelial cell injuries and diffuse microvascular thrombosis are also prominent features of heatstroke $(2,10,11)$. However, as a physical stress, heat stress can also induce cellular heat shock responses, which are characterized by anti-inflammatory medium and the expression of protective heat shock proteins (HSPs), and these protect cells from delayed injury stimulation, including ischemia/reperfusion and oxidative injury (12-14). Therefore, the present study aimed to examine the types of injuries induced in endothelial cells in the complex condition in which endothelial cells are stimulated by hyperthermia and gut-derived endotoxemia.

Cellular apoptosis is typically considered to be the predominant reason for organ dysfunction, and studies have suggested that endothelial cell apoptosis appears to be a mechanism of heatstroke $(2,11,15)$. However, the detailed molecular changes in endothelial cell apoptosis, which are induced by heat stress remain to be fully elucidated. To examine apoptosis in the vascular endothelium during heatstroke, an in vitro model of human umbilical vascular endothelial cells (HUVECs) stimulated with heat stress and lipopolysaccharide (LPS) was used to mimic the in vivo micro-environment of a direct heat attack and subsequent gut-derived endotoxemia. Furthermore, heat stress can induce increases in the expression levels of various HSPs, including HSP27, HSP90 and small molecular mass HSPs, which may be responsible for protection against cellular injury and apoptosis (15-18). B-cell lymphoma 2 (Bcl-2) is considered to be an important apoptosis-associated protein (19), and p38 mitogen-activated protein kinase (MAPK) has been found to affect a multitude of cellular events, including cell growth and death, differentiation and inflammation, in response to oxidative stress and LPS $(20,21)$. Therefore, the HSP27, HSP90, Bcl-2 and p38 MAPK proteins were selected in the present study as candidates for further investigation of the possible molecular mechanisms of endothelial apoptosis in the above-mentioned complex condition of heatstroke, so as to provide a potential therapeutic method for the prevention of sepsis-induced endothelial injury.

\section{Materials and methods}

Endothelial cells. The HUVECs were harvested from umbilical cords by collagenase treatment, as previously described $(22,23)$. Briefly, umbilical cords (length, 20-30 cm) were obtained from patients at the Victoria Hospital (London, ON, Canada) between October 2013 and June 2014, with 1-2 patients per week. All procedures relevant to HUVEC isolation were approved by the Human Ethics Committee of the University of Western Ontario (London, ON, Canada). The umbilical vein was washed and digested with $0.2 \%$ collagenase solution (Roche Applied Science, Mannheim, Germany). The detached endothelial cells were plated in Medium 199 (Gibco; Thermo Fisher Scientific, Inc., Waltham, MA, USA) supplemented with $10 \%$ heat-inactivated fetal calf serum (GE Healthcare Life Sciences, Logan, TX, USA), thymidine (2.4 mg/l; Sigma-Aldrich, St. Louis, MO, USA), glutamine
(230 mg/l; JRH Biosciences, Lenexa, KS, USA), heparin sodium (10 U/ml; Sigma-Aldrich), antibiotics (100 IU/ml penicillin, $100 \mu \mathrm{g} / \mathrm{ml}$ streptomycin and $0.125 \mu \mathrm{g} / \mathrm{ml}$ amphotericin B) and endothelial cell growth factor $(80 \mu \mathrm{g} / \mathrm{ml}$; Biomedical Technologies Inc., Stoughton, MA, USA). The cell cultures were incubated at $37^{\circ} \mathrm{C}$ in a humidified atmosphere with $5 \% \mathrm{CO}_{2}$ and expanded by brief trypsinization using $0.25 \%$ trypsin in phosphate-buffered saline (PBS), containing $0.02 \%$ EDTA (Gibco; Thermo Fisher Scientific, Inc.). The first to third passage HUVECs were used in the experiments. The study was approved by the ethics committee of the University of Western Ontario.

Drugs and treatment. LPS and SB203580, a specific inhibitor of p38 MAPK, were purchased from Sigma-Aldrich and Enzo Life Sciences (Farmingdale, NY, USA), respectively. The cells $\left(1 \times 10^{5}\right)$ were plated and incubated for $24 \mathrm{~h}$ at $37^{\circ} \mathrm{C}$, then treated with LPS $(1 \mu \mathrm{g} / \mathrm{ml})$ for $24 \mathrm{~h}$ at $37^{\circ} \mathrm{C}$. Heat stress was induced at $43^{\circ} \mathrm{C}$ for $1 \mathrm{~h}$ on aluminum plates within a tissue culture incubator to ensure temperature uniformity. Following the heat stress, the cultures were transferred to the standard $37^{\circ} \mathrm{C}$ incubator for another $23 \mathrm{~h}$. The combination of heat stress and LPS treatment was administered by applying heat stress at $43^{\circ} \mathrm{C}$ for $1 \mathrm{~h}$, followed by exposure to $1 \mu \mathrm{g} / \mathrm{ml}$ LPS for another $23 \mathrm{~h}$. SB203580 was applied for $1 \mathrm{~h}$ prior to the other treatments.

Caspase-3 activity. Cellular caspase-3 activity was measured using a caspase-3 fluorescent assay kit, according to manufacturer's protocol (cat. no. C002A20; Thomas Scientific, Swedesboro, NJ, USA). The cells were harvested and washed with cold Dulbecco's PBS. The cell pellet was resuspended in ice-cold lysis buffer (50 mM HEPES, pH 7.4, 0.1\% CHAPS, $5 \mathrm{mM}$ DTT, $0.1 \mathrm{mM}$ EDTA; all chemical reagents were purchased from Sigma-Aldrich). Following incubation on ice, the lysate was centrifuged at $10,000 \mathrm{x} \mathrm{g}$ at $4^{\circ} \mathrm{C}$ for $10 \mathrm{~min}$. The resulting supernatant was used for the measurement of caspase-3 activity, and the protein concentrations were quantified using a micro BCA protein assay kit (cat. no. 23227; Pierce Biotechnology, Inc., Rockford, IL, USA). The samples (50 $\mu \mathrm{g}$ protein) were incubated in duplicate with the caspase-3 substrate, Ac-DEVD-AMC, or Ac-DEVD-AMC and the inhibitor, Ac-DEVD-CHO, at $37^{\circ} \mathrm{C}$ for $2 \mathrm{~h}$ prior to measurements of caspase-3 activity, which were obtained with a fluorescent spectrophotometer (Wallac Victor 31420 Multi-Label Counter; PerkinElmer, Inc., Waltham, MA, USA), with excitation at $380 \mathrm{~nm}$ and emission at $405 \mathrm{~nm}$. The signals from the inhibitor-treated samples served as the background.

DNA fragmentation. The HUVECs were pre-labeled with BrdU (Roche Applied Science) for $24 \mathrm{~h}$ at $37^{\circ} \mathrm{C}$ prior to the other treatments. DNA fragmentation was measured using a Cellular DNA Fragmentation ELISA kit (cat. no. 11585045001; Roche Applied Science), according to the manufacturer's protocol.

Cellviability.Cellviabilitywasevaluatedusinga3-(4,5-dimethyl thiazol-2-yl)-2,5-diphenyl tetrazolium bromide (MTT) assay kit (cat. no. 11465007001; Roche Applied Science), according 
to the manufacturer's protocol. Briefly, $1 \times 10^{4}$ cells were plated in 96-well microplates at a final volume of $100 \mu$ l culture medium (serum-free Medium 199) per well in a humidified atmosphere $\left(37^{\circ} \mathrm{C} ; 5 \% \mathrm{CO}_{2}\right)$. After the incubation period $(24 \mathrm{~h})$ and treatment with LPS and heat stress, $10 \mu \mathrm{l}$ MTT labeling reagent (final concentration, $0.5 \mathrm{mg} / \mathrm{ml}$ ) was added to each well. The microplate was incubated for $4 \mathrm{~h}$ in a humidified atmosphere $\left(37^{\circ} \mathrm{C} ; 5 \% \mathrm{CO}_{2}\right)$. Solubilization solution $(100 \mu \mathrm{l})$ was added to each well. The plate was allowed to stand overnight in the humidified atmosphere of the incubator. Upon complete solubilization of purple formazan crystals, the spectrophotometrical absorbance of the samples was measured using a microplate reader (Bio-Rad Laboratories, Inc., Hercules, CA, USA) at a wavelength of $550 \mathrm{~nm}$.

Western blot analysis. Protein samples were extracted from the cultured HUVECs in extraction buffer [20 $\mathrm{mM}$ Tris, pH 0.5, $150 \mathrm{mM} \mathrm{NaCl}, 1.0 \mathrm{mM}$ EDTA, $1.0 \mathrm{mM}$ EGTA, 0.1\% Triton X-100, $2.5 \mathrm{mM}$ sodium pyrophosphate (Sigma-Aldrich), $1.0 \mathrm{mM} \beta$-pyrophosphate glycerol (Sigma-Aldrich)], which was supplemented with $1.0 \mathrm{mM} \mathrm{Na}_{3} \mathrm{Vo}_{4}$ (Sigma-Aldrich), 1.0 $\mathrm{mM}$ phenylmethanesulfonyl fluoride (Sigma-Aldrich) and a protease inhibitor cocktail. Following centrifugation at $10,000 \mathrm{x} \mathrm{g}$ for $15 \mathrm{~min}$ at $4^{\circ} \mathrm{C}$, the supernatant was collected and the protein concentrations were quantified using the micro BCA protein assay kit. Equal quantities of protein $(50 \mu \mathrm{g})$ were subjected to SDS-PAGE (10 or 12\%). After separation with SDS-PAGE, the upper side of the sample wells was removed with a razor blade. The bottom right-hand corner of the gel was notched for orientation purposes, and the gel was placed in $1 \mathrm{X}$ transfer buffer (Sigma-Aldrich). PVDF membranes (EMD Millipore, Billerica, MA, USA) were sliced, according to the size of the gel, and incubated in $95 \%$ methanol for $\sim 1$ min on a rocker at room temperature. The methanol was removed and the membrane was equilibrated in $1 \mathrm{X}$ transfer buffer (Sigma-Aldrich; $400 \mathrm{ml}$ methanol, $200 \mathrm{ml}$ 10X transfer buffer and $1,400 \mathrm{ml}$ water). The membrane was subjected to $100 \mathrm{~V}$ (constant voltage) for $1 \mathrm{~h}$ at $4^{\circ} \mathrm{C}$. The membrane was washed with $10 \mathrm{ml}$ Tris-buffered saline (TBS) buffer [Sigma-Aldrich; $1.22 \mathrm{~g}$ Tris $(10 \mathrm{mM})$ and $8.78 \mathrm{~g} \mathrm{NaCl}(150 \mathrm{mM})$ to 1 liter distilled water and $\mathrm{pH}$ was adjusted to 7.5 with $\mathrm{HCl}$ ] and $5 \%$ blocking buffer (Sigma-Aldrich; $0.5 \mathrm{~g}$ bovine serum albumin in TBS and Tween 20 buffer to a final volume of $10 \mathrm{ml}$ ); the membrane was gently agitated for $\geq 1 \mathrm{~h}$. The $5 \%$ blocking buffer was removed and the membrane was rinsed three times, with TBST (5 min per wash).

The primary antibodies used were as follows: Rabbit monoclonal anti-human Bcl-2 (cat. no. 2780), rabbit monoclonal anti-human HSP90 (cat. no. 4874), rabbit anti-human phosphorylated-p38 (cat. no. 9211), and rabbit anti-human total p38 (cat. no. 9212; all 1:1,000 dilution), and all were obtained from Cell Signaling Technology, Inc. (Danvers, MA, USA). Mouse monoclonal anti-human HSP27 (cat. no. 12215; 1:1,000 dilution) was obtained from Cayman Chemistry Company (Ann Arbor, MI, USA) and rabbit anti-GAPDH (cat. no. sc-25778; 1:1,000 dilution) served as an internal control, and was obtained from Santa Cruz Biotechnology, Inc. (Dallas, Tx, USA). These primary antibodies were added at the appropriate dilution to $10 \mathrm{ml} \mathrm{5 \%}$ blocking buffer and agitated gently for $\geq 1 \mathrm{~h}$. The first antibody solution was discarded and the membrane was washed twice for 10 min with TBST buffer. The horseradish peroxidase (HRP)-conjugated secondary antibodies [goat anti-rabbit (cat. no. 172-1019) or goat anti-mouse (cat. no. 170-6515) IgG-HRP (all 1:1,000 dilution; Bio-Rad Laboratories, Inc.)] were added at the appropriate dilution to $5 \mathrm{ml} \mathrm{5 \%}$ blocking buffer and agitated gently for $\geq 1 \mathrm{~h}$. The secondary antibody solution was discarded and the membrane was washed twice for $10 \mathrm{~min}$ with TBST buffer. The PVDF membranes were subsequently developed using a chemiluminescence kit [West-zol ${ }^{\circledR}$ (plus); Intron Biotechnology, Inc., Seoul, South Korea]. The bands were quantified using densitometry and GelQuant Pro software version 1.0 (MicroChemi; FroggaBio Inc., Toronto, ON, Canada).

Statistical analysis. All data are presented as the mean \pm standard deviation and were analyzed using SPSS 15.0 (SPSS Inc., Chicago, IL, USA). For multi-group comparisons, analysis of variance followed by Newman-Keuls tests were performed. $\mathrm{P}<0.05$ was considered to indicate a statistically significant difference.

\section{Results}

Effects of heat stress and LPS on caspase-3 activity, DNA fragmentation and the MTT assay. The cells were treated with heat stress, LPS or the combination of heat stress pretreatment followed by LPS. Caspase-3 activity, DNA fragmentation and cell viability were detected as indicators of cellular apoptosis. The results revealed that LPS increased caspase-3 activity, DNA fragmentation and cell viability; and these effects were rescued by heat stress pretreatment (Fig. 1). These findings indicated that heat stress pretreatment inhibited LPS-induced apoptosis in the HUVECs.

Effects of heat stress and LPS on the expression levels of HSP27, HSP9O and Bcl-2. The treatments described above were performed, and the expression levels of HSP27, HSP90 and Bcl-2 were determined using Western blot analysis. As shown in Fig. 2, LPS decreased the expression levels of HSP27, HSP90 and Bcl-2, and heat stress significantly increased the expression levels of these proteins under normal and LPS-stimulated conditions (Fig. 2A and B). As protective proteins, the changes in the expression levels of these three proteins suggested that they may be involved in the protective role of heat stress against LPS-induced HUVEC apoptosis.

Effects of heat stress and LPS on the phosphorylation of p38. To investigate the protective mechanisms underlying the effect of heat stress pretreatment against LPS-induced endothelial apoptosis in more detail, the expression levels of total and phosphorylated p38 were determined using Western blot analysis. Similar to the observed changes in cellular apoptosis, LPS increased the phosphorylation of $\mathrm{p} 38$, and heat stress decreased the baseline level and LPS-induced high phosphorylation level of p38 (Fig. 2C and D).

Roles of p38 in heat stress and LPS-stimulation of apoptosis in HUVECs. The specific inhibitor of p38, SB203580, was used to further determine the role of p38 in heat stress and the subsequent LPS-induced apoptosis of HUVECs. The results revealed that SB203580 decreased LPS-induced caspase-3 activation. In 
A

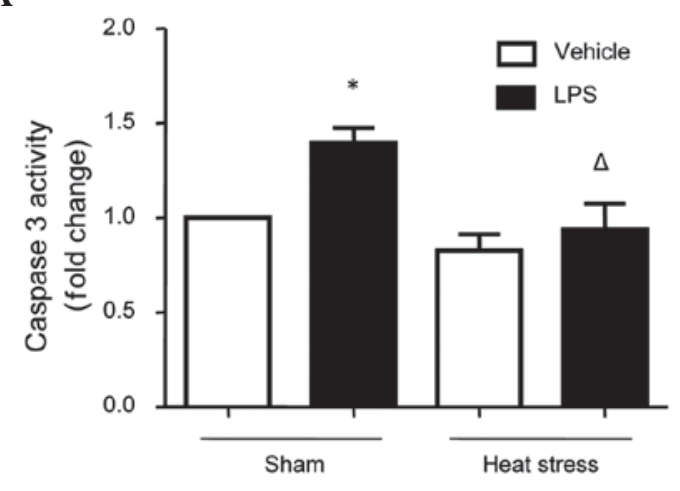

B

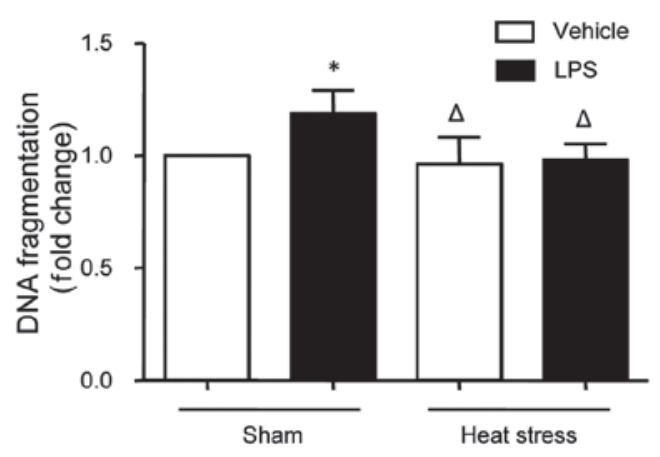

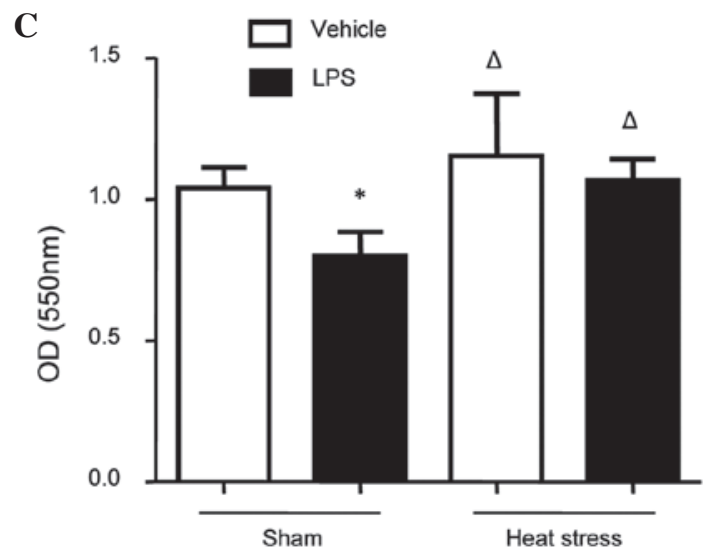

Figure 1. Changes in caspase-3 activity, DNA fragmentation and the cell viability in human umbilical vein endothelial cells stimulated by heat stress followed by LPS. The cells were treated with either heat stress $\left(43^{\circ} \mathrm{C}\right.$ for $1 \mathrm{~h}$, followed by $37^{\circ} \mathrm{C}$ for $\left.23 \mathrm{~h}\right), \mathrm{LPS}(1 \mu \mathrm{g} / \mathrm{ml}$ for $24 \mathrm{~h}) \mathrm{or}$ the combination of heat stress $\left(43^{\circ} \mathrm{C}\right.$ for $1 \mathrm{~h}$ ), followed by LPS ( $1 \mu \mathrm{g} / \mathrm{ml}$ for $23 \mathrm{~h}$ ). (A) Caspase-3 activities, (B) DNA fragmentation and (C) cell viability, determined using an MTT assay, were measured. The results indicated that cellular apoptosis was increased, as indicated by high levels of caspase-3 activity and DNA fragmentation, and low OD values in the MTT assay. The data are presented as the mean \pm standard deviation from five independent experiments. ${ }^{*} \mathrm{P}<0.05$, vs. sham vehicle group; ${ }^{\wedge} \mathrm{P}<0.05$, vs. sham LPS group. LPS, lipopolysaccharide; MTT, 3-(4, 5-dimethyl thiazol-2-yl)-2,5-diphenyl tetrazolium bromide; OD, optical density.

addition, SB203580 reduced the LPS-induced elevation in DNA fragmentation (Fig. 3). No changes in DNA fragmentation were found following the SB203580 and heat stress treatment (data not shown). Based on these data, it was concluded that heat stress pretreatment inhibited LPS-induced apoptosis by attenuating the activation of p38 MAPK.

Role of p38 MAPK in the expression levels of HSP27, HSP90 and $\mathrm{Bcl}-2$. The results described above demonstrated that heat stress pretreatment inhibited LPS-induced apoptosis by attenuating the activation of p38 MAPK, and that heat stress also increased the expression levels of HSP27, HSP90 and Bcl-2. To further determine the role of p38 activation on the expression levels of HSP27, HSP90 and Bcl-2 in the HUVECs, the cells were pretreated with SB203580 for $1 \mathrm{~h}$, and then stimulated with LPS. The expression levels of HSP27, HSP90 and Bcl-2 were determined using Western blot analysis. The results revealed that SB203580 had a similar effect as heat stress by directly increasing the expression levels of these proteins and inhibiting the LPS-induced downregulation of these proteins (Fig. 4).

\section{Discussion}

In the present study, the in vivo micro-environment of direct heat attack followed by stimulation with gut-derived endotoxemia during heatstroke was investigated using an in vitro model of HUVECs, which were stimulated with heat stress and LPS. This was performed to investigate the possible changes in the vascular endothelium and the associated signaling pathways. The present study demonstrated that LPS activated p38 MAPK, which then increased endothelial apoptosis, as indicated by the observed high level of caspase-3 activity, increased levels of DNA fragmentation and decreased cellular viabilities. Heat stress pretreatment inhibited LPS-induced apoptosis by attenuating p38 MAPK, and further increasing the expression levels of Bcl-2, HSP27 and HSP90.

Roles of heat stress and LPS in apoptosis. The apoptosis of vascular endothelial cells has been associated with impairments of endothelial function and organ injury during sepsis, and LPS-induced caspase- 3 activation and apoptosis in the endothelium have previously been reported, including in our previous investigations $(24,25)$. In the present study, similar results were found, and revealed that LPS increased apoptosis, as indicated by the elevated caspase- 3 activity, DNA fragmentation and decreased cell viability in the HUVECs. However, heat stress pretreatment exerted effects, which were opposite to those of LPS. The heat, which induces heatstroke is known to be directly cytotoxic, and studies in cell lines and animal models have 
A

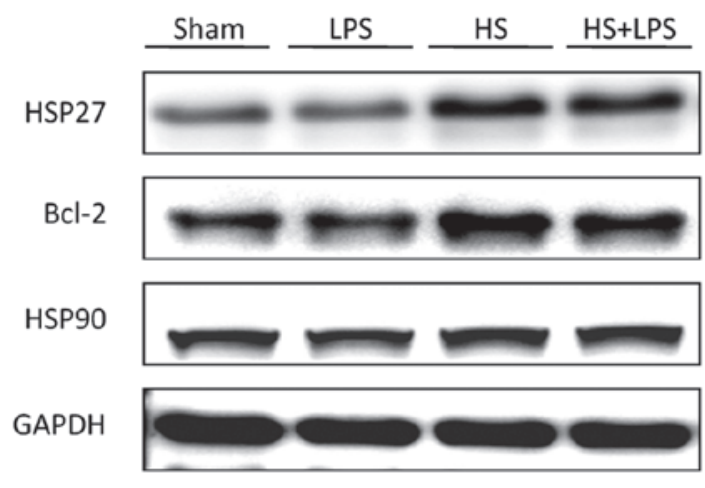

$\mathbf{C}$

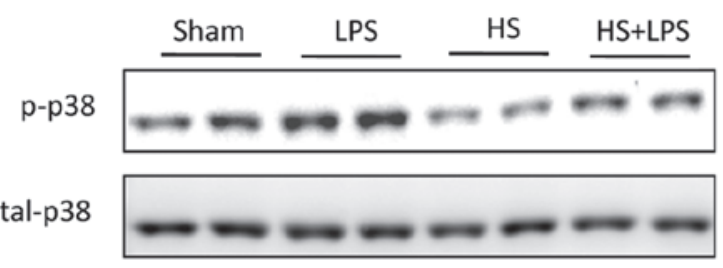

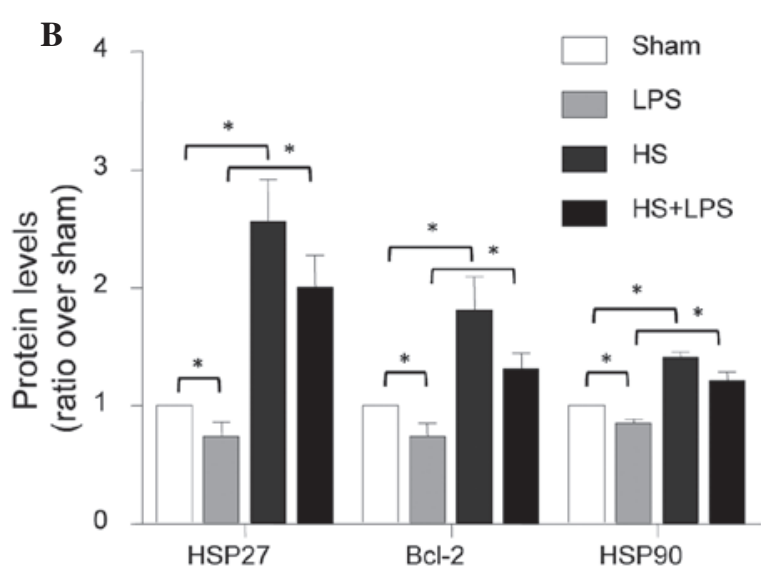

D

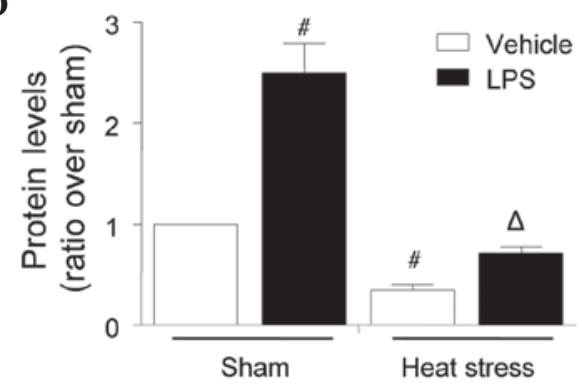

Figure 2. Changes in the expression levels of HSP27, Bcl-2 and HSP90, and p-p38 phosphorylation in human umbilical vein endothelial cells stimulated with heat stress and LPS. The cells were treated with heat stress $\left(43^{\circ} \mathrm{C}\right.$ for $1 \mathrm{~h}$, followed by $37^{\circ} \mathrm{C}$ for $\left.23 \mathrm{~h}\right), \mathrm{LPS}(1 \mu \mathrm{g} / \mathrm{ml}$ for $24 \mathrm{~h})$ or the combination of heat stress $\left(43^{\circ} \mathrm{C}\right.$ for $\left.1 \mathrm{~h}\right)$, followed by LPS $(1 \mu \mathrm{g} / \mathrm{ml}$ for $23 \mathrm{~h}$ ). (A) Expression levels of HSP27, HSP90 and Bcl-2 were determined using Western blot analysis (B) Corresponding bands were quantified using densitometry (protein/GAPDH) and are presented as fold changes relative to the sham group. (C) Expression levels of total and phosphorylated p38 were determined using Western blot analysis. (D) Corresponding bands were quantified using densitometry (phosphorylated/total protein) and are presented as fold changes relative to the sham group. The data are presented as the mean \pm standard deviation from three independent experiments. "P $<0.05$, between the indicated groups; ${ }^{*} \mathrm{P}<0.05$, vs. sham vehicle group; ${ }^{\mathrm{P}} \mathrm{P}<0.05$, vs. sham LPS group. HSP, heat shock protein; Bcl-2, B-cell lymphoma 2; p-p38, phosphorylated p38; LPS, lipopolysaccharide; HS, heat stress.

A

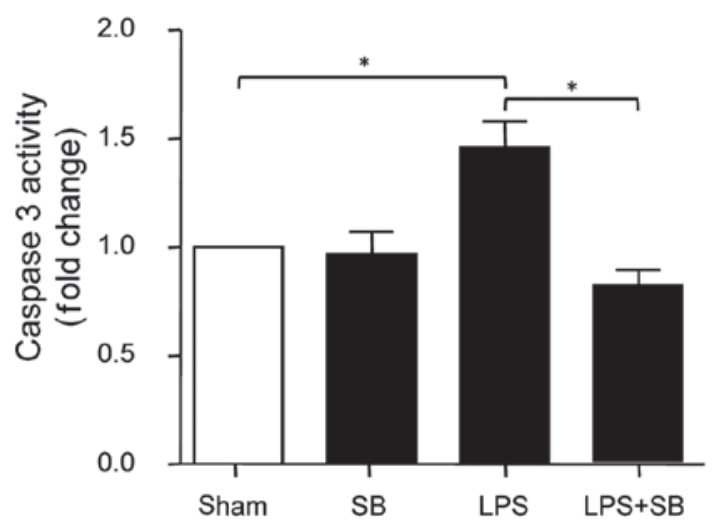

B

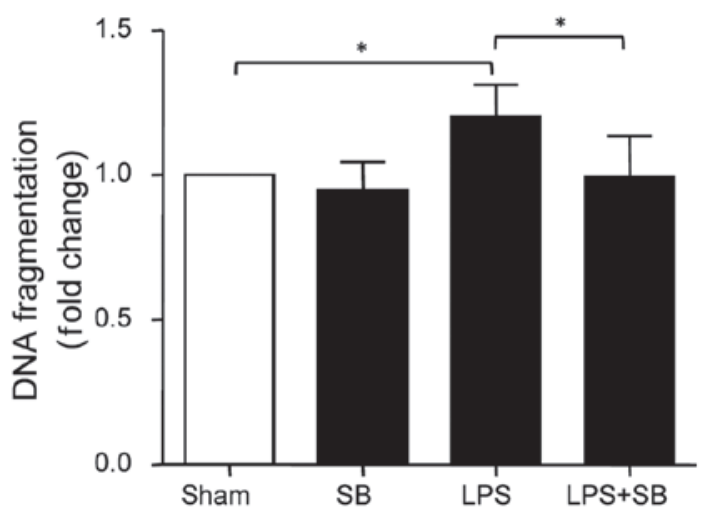

Figure 3. Changes in caspase-3 activity and DNA fragmentation in the human umbilical vein endothelial cells pretreated with SB203580 and then stimulated with heat stress and LPS. The cells were treated with $10 \mathrm{mmol} / 1 \mathrm{SB} 203580$ (pecific inhibitor of p38) for $1 \mathrm{~h}$, followed by heat stress $\left(43^{\circ} \mathrm{C}\right.$ for $1 \mathrm{~h}$, followed by $37^{\circ} \mathrm{C}$ for $\left.23 \mathrm{~h}\right)$, LPS $(1 \mu \mathrm{g} / \mathrm{ml}$ for $24 \mathrm{~h})$ or a combination of heat stress $\left(43^{\circ} \mathrm{C}\right.$ for $\left.1 \mathrm{~h}\right)$ followed by LPS $(1 \mu \mathrm{g} / \mathrm{ml}$ for $23 \mathrm{~h})$. (A) Caspase-3 activity and (B) DNA fragmentation were measured. No changes in DNA fragmentation due to heat stress treatment were observed; data not shown). The data are presented as the mean \pm standard deviation from five independent experiments. " $\mathrm{P}<0.05$ between the indicated groups. LPS, lipopolysaccharide; SB, SB203580.

suggested that heat can directly induce tissue injury $(2,26)$. However, as a physical stress, the protective role of heat stress has also been reported, which is similar to the protective effect of hypoxia in ischemia/reperfusion-induced apoptosis. For example, the protective role of heat shock on cardiomyocytes, following injury of the cells by ischemia/reperfusion has been well reviewed (27). In addition, it has been observed that heat stress preconditioning can prevent the endothelial coronary dysfunction that is induced by ischemia and reperfusion $(28,29)$. The varied nature of the findings described above may be due to the severity and timing of heat stress, and the heat tolerances of different cell lines. (30-32). In conclusion, the evidence from 
A

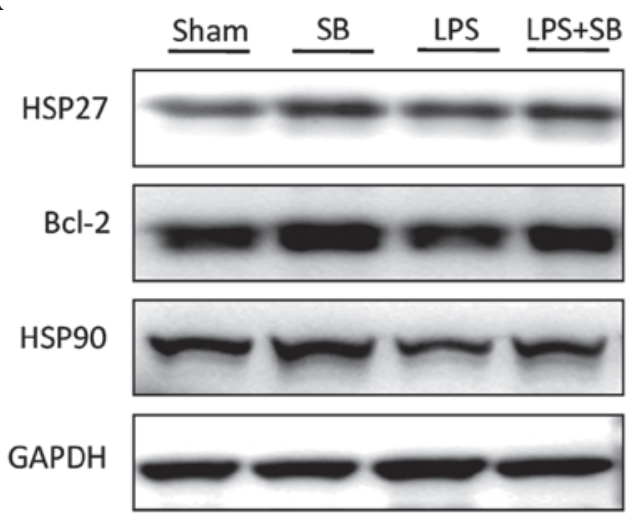

B

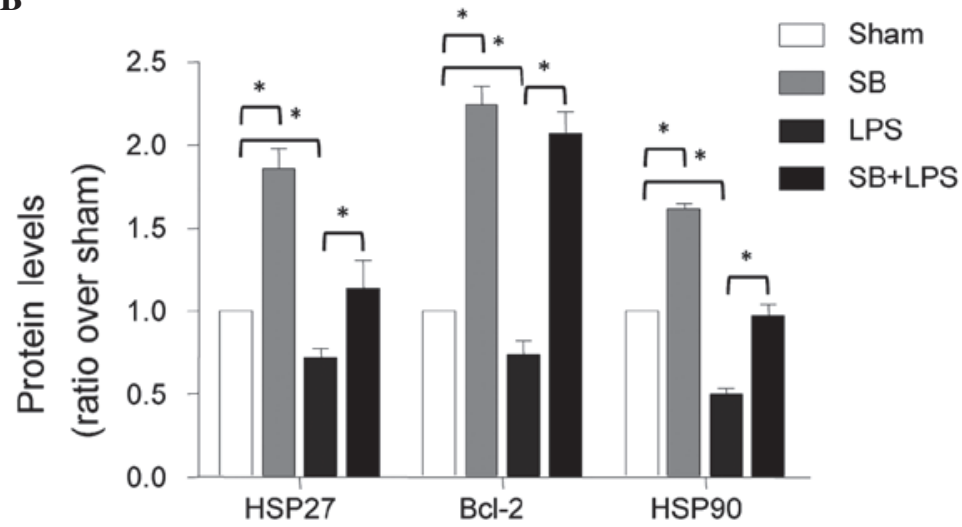

Figure 4. Changes in the expression levels of Bcl-2, HSP90 and HSP27 in human umbilical vein endothelial cells pretreated with SB203580 and then stimulated with LPS. The cells were treated with $10 \mathrm{mmol} / 1 \mathrm{SB} 203580$ for $1 \mathrm{~h}$ followed by LPS (1 $\mu \mathrm{g} / \mathrm{ml}$ for $24 \mathrm{~h})$. (A) Expression levels of Bcl-2, HSP90 and HSP27 following SB203580 pretreatment and LPS stimulation were determined using Western blot analysis. (B) Corresponding bands were quantified using densitometry (protein/GAPDH) and are presented as fold changes relative to the sham group. The data are presented as the mean \pm standard deviation from three independent experiments. ${ }^{*} \mathrm{P}<0.05$ between the indicated groups. HSP, heat shock protein; Bcl-2, B-cell lymphoma 2; LPS, lipopolysaccharide; SB, SB203580.

the present study regarding caspase-3 activation and high levels of DNA fragmentation demonstrated that heat stress pretreatment decreased LPS-induced apoptosis in the HUVECs via the caspase-3 pathway.

Role of the p38-HSP/Bcl-2 pathway in heat stress and LPS-induced apoptosis. Heat stress alone had a protective effect against LPS-induced endothelial apoptosis; thus the present study aimed to determine how this effect was mediated. In the present study, three protective proteins, HSP27, HSP90 and Bcl-2, were selected as candidates for roles in the protective effects of heat stress against apoptosis.

The results of the present study revealed that LPS decreased the expression levels of HSP27, HSP90 and Bcl-2, and that heat stress pretreatment significantly increased the expression levels of HSP27, HSP90 and Bcl-2. The possible protective roles of HSP27 and HSP90 have been observed in several studies, including those of heat stress-induced intestinal epithelial apoptosis (33) and LPS-induced endothelial barrier dysfunction (34). In addition, HSP90 inhibits cell apoptosis by inhibiting the activity of proapoptotic kinase apoptosis signal-regulating kinase 1 (17). The results of the present study reinforce the cytoprotective mechanisms of the chaperoning HSPs. The founding member of the Bcl-2 family of regulator proteins is Bcl-2, and cell death is regulated by either the induction (anti-apoptotic) or inhibition (pro-apoptotic) of $\mathrm{Bcl}-2$. The $\mathrm{Bcl}-2$ protein is specifically considered to be an important anti-apoptotic protein, and represents an important apoptotic pathway (19). In the present study, the expression levels of Bcl-2 were decreased by LPS stimulation and increased by heat stress, which indicated that the heat stress pretreatment-induced decrease in LPS-induced HUVEC apoptosis was mediated through the anti-apoptotic Bcl-2 pathway.

MAPKs include three well-characterized subfamilies of protein kinases: Extracellular signal-regulated kinases (ERK1/2), p38 kinases and c-Jun NH2-terminal kinases (JNK1/2/3). The activations of each of the three subfamilies have been implicated in gene expression during pathological and physiological conditions, and p38 MAPK has been found to affect a multitude of cellular events, including cell growth and death, differentiation and inflammation, in response to oxidative stress and LPS $(20,21)$. The present study also demonstrated that LPS increased p38 activation, and that heat stress decreased baseline and LPS-induced high phosphorylation levels of $\mathrm{p} 38$. In addition, the specific inhibitor of $\mathrm{p} 38$, SB203580, attenuated LPS-induced apoptosis in the HUVECs. Similarly, it has been reported that LPS stimulation induces p38 MAPK phosphorylation in HMVEC-Ls (35).

Following the observation in the present study that HSP27 and HSP90 may have functions in heat stress, the subsequent step in further investigating the signaling pathway involved in the protective effects of heat stress against apoptosis was to determine the association between these proteins and the activation of p38. To investigate this, SB203580 was used, and it was found that pretreatment with SB203580 had the same effects as heat stress on the LPS-induced downregulation of HSP27 and HSP90. In addition, SB203580 was found to rescue the LPS-induced downregulation of Bcl-2; this finding suggested that LPS-induced HUVEC apoptosis and the protective role of heat stress were mediated through the p38-HSP/Bcl-2 pathway.

In conclusion, the present study demonstrated that heat stress pretreatment decreased LPS-induced Bcl-2-associated apoptosis by attenuating the activation of $\mathrm{p} 38$, which increased the expression levels of HSP27 and HSP90 in the HUVECs. These findings provide novel evidence that, in conditions of sepsis, heat stress pre-treatment may be useful as a therapeutic strategy for the prevention of endothelial injury. During this process, p38 may be a potential therapeutic target for the treatment of endothelial dysfunction and organ injury. However, further in vivo investigations, particularly those involving gene-knockout animal models, are warranted to clarify these roles.

\section{Acknowledgements}

This study was supported by grants from the National Natural Science Foundation of China (grant no. 81101467), the Project Team of Natural Science Foundation of Guangdong 
Province (grant no. s2013030013217), the Project of Medical Research of PLA (grant no. BWS12J108), the Guangdong Province Science and Technology Planning Project of China (grant no. 2102B031800416) and the Heart \& Stroke Foundation of Canada (grant no. T6717; awarded to Professor Tianqing Peng of the University of Western Ontario, London, Canada). Professor Tianqing Peng is a recipient of the New Investigator Award from the Canadian Institutes of Health Research.

\section{References}

1. Varghese GM, John G, Thomas K, Abraham OC and Mathai D: Predictors of multi-organ dysfunction in heatstroke. Emerg Med J 22: 185-187, 2005.

2. Bouchama A and Knochel JP: Heat stroke. N Engl J Med 346: 1978-1988, 2002.

3. Leon LR and Helwig BG: Heat stroke: Role of the systemic inflammatory response. J Appl Physiol (1985) 109: 1980-1988, 2010.

4. Leon LR, Blaha MD and DuBose DA: Time course of cytokine, corticosterone and tissue injury responses in mice during heat strain recovery. J Appl Physiol (1985) 100: 1400-1409, 2006

5. Lim CL and Mackinnon LT: The roles of exercise-induced immune system disturbances in the pathology of heat stroke: The dual pathway model of heat stroke. Sports Med 36: 39-64, 2006.

6. Bouchama A, Roberts G, Al Mohanna F, El-Sayed R, Lach B Chollet-Martin S, Ollivier V, Al Baradei R, Loualich A, Nakeeb S, et al: Inflammatory, hemostatic and clinical changes in a baboon experimental model for heat stroke. J Appl Physiol (1985) 98: 697-705, 2005.

7. Lambert GP: Intestinal barrier dysfunction, endotoxemia and gastrointestinal symptoms: The 'canary in the coal mine' during exercise-heat stress? Med Sport Sci 53: 61-73, 2008.

8. de Pablo R, Monserrat J, Reyes E, Díaz D, Rodríguez-Zapata M, de la Hera A, Prieto A and Álvarez-Mon M: Circulating sICAM-1 and sE-Selectin as biomarker of infection and prognosis in patients with systemic inflammatory response syndrome. Eur J Intern Med 24: 132-138, 2013.

9. TIba T, Gando S, Murata A, Kushimoto S, Saitoh D, Eguchi Y, Ohtomo Y, Okamoto K, Koseki K, Mayumi T, et al: Predicting the severity of systemic inflammatory response syndrome (SIRS)-associated coagulopathy with hemostatic molecular markers and vascular endothelial injury markers. J Trauma 63 1093-1098, 2007.

10. Roberts GT, Ghebeh H, Chishti MA, Al-Mohanna F, El-Sayed R, Al-Mohanna F and Bouchama A: Microvascular injury, thrombosis, inflammation and apoptosis in the pathogenesis of heatstroke a study in baboon model. Arterioscl Throm Vasc Biol 28: 1130-1136, 2008.

11. Bouchama A, Hammami MM, Haq A, Jackson J and al-Sedairy S: Evidence for endothelial cell activation/injury in heatstroke. Crit Care Med 24: 1173-1178, 1996.

12. Gray CC, Amrani M and Yacoub MH: Heat stress proteins and myocardial protection: Experimental model or potential clinical tool? Int J Biochem Cell Biol 31: 559-573, 1999.

13. Sugimoto N, Shido O, Matsuzaki K, Katakura M, Hitomi Y, Tanaka M, Sawaki T, Fujita Y, Kawanami T, Masaki Y, et al: Long-term heat exposure prevents hypoxia-induced apoptosis in mouse fibroblast cells, Cell Biochem Biophys 70: 301-307, 2014.

14. Gill RR, Gbur CJ Jr, Fisher BJ, Hess ML, Fowler AA III, Kukreja RC and Sholley MM: Heat shock provides delayed protection against oxidative injury in cultured human umbilical vein endothelial cells. J Mol Cell Cardiol 30: 2739-2749, 1998.

15. Brinton MR, Tagge CA, Stewart RJ, Cheung AK, Shiu YT and Christensen DA: Thermal sensitivity of endothelial cells on synthetic vascular graft material. Int J Hyperthermia 28 : 163-174, 2012.
16. Mestril R and Dillmann WH: Heat shock proteins and protection against myocardial ischemia. J Mol Cell Cardiol 27: 45-52, 1995

17. Zhang R, Luo D, Miao R, Bai L, Ge Q, Sessa WC and Min W: Hsp90-Akt phosphorylates ASK1 and inhibits ASK1-mediated apoptosis. Oncogene 24: 3954-3963, 2005.

18. Kabakov AE, Budagova KR, Bryantsev AL and Latchman DS: Heat shock protein 70 or heat shock protein 27 overexpressed in human endothelial cells during posthypoxic reoxygenation can protect from delayed apoptosis. Cell Stress Chaperones 8: 335-347, 2003.

19. Zakeri Z and Lockshin RA: Cell death: History and future. Adv Exp Med Biol 615: 1-11, 2008.

20. Ono $\mathrm{K}$ and Han J: The p38 signal transduction pathway: Activation and function. Cell Signal 12: 1-13, 2000.

21. Peng T, Lu X and Feng Q: NADH oxidase signaling induces cyclooxygenase-2 expression during lipopolysaccharide stimulation in cardiomyocytes. FASEB J 19: 293-295, 2005.

22. Mizuguchi S, Stephen J, Bihari R, Markovic N, Suehiro S, Capretta A, Potter RF and Cepinskas G: CORM-3-derived CO modulates polymorphonuclear leukocyte migration across the vascular endothelium by reducing levels of cell surface-bound elastase. Am J Physiol Heart Circ Physiol 297: H920-H929, 2009.

23. Yoshida N, Granger DN, Anderson DC, Rothlein R, Lane C and Kvietys PR: Anoxia/reoxygenation-induced neutrophil adherence to cultured endothelial cells. Am J Physiol 262: H1891-H1898, 1992.

24. Suzuki K, Murakami T, Kuwahara-Arai K, Tamura H, Hiramatsu K and Nagaoka I: Human anti-microbial cathelicidin peptide LL-37 suppresses the LPS-induced apoptosis of endothelial cells. Int Immunol 23: 185-193, 2011.

25. Hu H, Li X, Li Y, Wang L, Mehta S, Feng Q, Chen R and Peng T: Calpain-1 induces apoptosis in pulmonary microvascular endothelial cells under septic conditions. Microvasc Res 78: 33-39, 2009.

26. Moulin M and Arrigo AP: Long lasting heat shock stimulation of TRAIL-induced apoptosis in transformed T lymphocytes. Exp Cell Res 312: 1765-1784, 2006.

27. Joyeux-Faure M, Arnaud C, Godin-Ribuot D and Ribuot C: Heat stress preconditioning and delayed myocardial protection: What is new? Cardiovasc Res 60: 469-477, 2003.

28. Joyeux M, Bouchard JF, Lamontagne D, Godin-Ribuot D and Ribuot C: Heat stress-induced protection of endothelial function against ischaemic injury is abolished by ATP-sensitive potassium channel blockade in the isolated rat heart. Br J Pharmacol 130: 345-350, 2000.

29. Amrani M, Corbett J, Allen NJ, O'Shea J, Boateng SY, May AJ, Dunn MJ and Yacoub MH: Induction of heat-shock proteins enhances myocardial and endothelial functional recovery after prolonged cardioplegic arrest. Ann Thorac Surg 57: 157-160, 1994.

30. Xu DZ, Lu Q, Swank GM and Deitch EA: Effect of heat shock and endotoxin stress on enterocyte viability apoptosis and function varies based on whether the cells are exposed to heat shock or endotoxin first. Arch Surg 131: 1222-1228, 1996.

31. Furusawa Y, Tabuchi Y, Wada S, Takasaki I, Ohtsuka K and Kondo T: Identification of biological functions and gene networks regulated by heat stress in U937 human lymphoma cells. Int J Mol Med 28: 143-151, 2011.

32. Heidemann SM and Glibetic M: Heat stress protects against lung injury in the neutropenic, endotoxemic rat. Inflammation 29: $47-53,2005$

33. Baird CH, Niederlechner S, Beck R, Kallweit AR and Wischmeyer PE: L-Threonine induces heat shock protein expression and decreases apoptosis in heat-stressed intestinal epithelial cells. Nutrition 29: 1404-1411, 2013.

34. Hirano S, Rees RS, Yancy SL, Welsh MJ, Remick DG, Yamada T, Hata J and Gilmont RR: Endothelial barrier dysfunction caused by LPS correlates with phosphorylation of HSP27 in vivo. Cell Biol Toxicol 20: 1-14, 2004.

35. Mizumura K, Gon Y, Kumasawa F, Onose A, Maruoka S, Matsumoto K, Hayashi S, Kobayashi T and Hashimoto S: Apoptosis signal-regulating kinase 1-mediated signaling pathway regulates lipopolysaccharide-induced tissue factor expression in pulmonary microvasculature. Int Immunopharmacol 10: $1062-1067,2010$ 